\title{
A EPISTEMOLOGIA DA EDUCAÇÃO ESCOLAR E A MÁSCARA DO SEU OBJETIVO EDUCACIONAL SOCIAL, IGUALITÁRIO E DEMOCRÁTICO.
}

\section{Antônio Carlos Coqueiro Pereira ${ }^{1}$}

\section{1 - RESUNO}

Neste trabalho, partido das ideias de Michel Foucault e de Pierre Bourdieu, sobre a educação e o papel da instituição chamada escola em ser democrática, igualitária na concepção dos seus objetivos para poder transformar o sujeito em um ser pensante, critico, transformador e condutor de atitudes que possa modificar a sua adversidade dentro de uma sociedade. Será que a instituição educacional escolar está tendo esses objetivos atualmente? A indignação é poder ver o discurso nos tempos contemporâneos que a instituição escola promove uma educação igualitária e democrática para a sua clientela. Com base na declaração que a escola e democrática e igualitária, vem a refutação, demonstrando pelos fatos a seguir desse Artigo, que a educação e a instituição chamada escola está longe de ser democrática e igualitária. Hoje pode observar um despreparo na formação continuada dos agentes que fazem o papel importante nesse processo que são os professores com práticas metodológicas capazes de poder favorecer a instituição escolar como mecanismo contra a alienação e por consequente, o pouco caso em que o sistema controlador dessas instituições fazem para o processo de formação continuada desses agentes. Para ter uma escola libertária, democrática e igualitária, está muito muito longe anos luz para poder ver o reflexo desse processo no meio social.

PALAVRA CHAVE: Escola Libertária; Escola Democrática; Escola Igualitária. 


\section{2 - ABSTRACT}

In this work, based on the ideas of Michel Foucault and Pierre Bourdieu, on education and the role of the institution called school in being democratic, egalitarian in the conception of its objectives to be able to transform the subject into a thinking, critical, transforming and conducting being of attitudes that can modify adversity within a society. Does the school educational institution currently have these goals? The indignation is to see the discourse in contemporary times that the school institution promotes an egalitarian and democratic education for its clientele. Based on the statement that the school is democratic and egalitarian, comes the refutation, demonstrating by the facts to follow of this Article, that education and the institution called school is far from being democratic and egalitarian. Today, there is a lack of preparation for the continuing education of the agents who play the important role in this process, which are the teachers with methodological practices able to favor the school institution as a mechanism against alienation and, consequently, the little case in which the controlling system of these institutions to the process of continuous training of these agents. To have a libertarian, democratic and egalitarian school, it is far too light years too long to be able to see the reflection of this process in the social environment.

KEY WORD: Libertarian School; Democratic School; Equal School. 


\section{3 - INTRODUÇÃO}

A elaboração desse Artigo Acadêmico tem por objetivo geral, tentar compreender como a epistemologia da educação escolar que deveria ser de uma educação social, democrática e igualitária, entender suas inferências positivas dentro da formação do educando para práticas de conhecimentos adquiridos nas quatro paredes da sala de aula no papel de escola para a sociedade. A metodologia é voltada para campo bibliográfico, com observações no Plano Político Pedagógico - PPP, quanto a metodologia aplicada na unidade escolar, tais como uso de metodologias em que seja capaz de transformar um cidadão ignorante em um ser educado e com o saber escolar preparado para ser um agente multiplicador de conhecimento, de postura e com atitudes que possam sobressair para o seu sustento e a manutenção da vida. Será que a pratica atual de metodologias colocadas em pratica pelos educadores e - sistema educacional está promovendo uma escola com uma educação epistemologicamente escolar, com intuito de promover um cidadão para um patamar mais elevado de conhecimento ou está usando uma máscara que esconde a atual situação de emprego metodológico que faz o aluno ser um alienado do sistema e das classes de elites para serem mais um empregado nos campos de obras? Será que os órgãos governamentais, que tem a função de fornecer uma capacitação continuada está tendo e colocando em pratica o que dá sua função para a preparação desses educadores? Para melhor compreender sobre essa inquietação, será pesquisado Henry Wallon, Michel Foucault, Pierre Bourdieu e outros para pesquisa e fontes de compreensão. Esta resposta vem ser questionada para uma possível solução para que tenhamos uma escola social, com igualdade, democracia e libertaria para poder fazer com que a clientela escolar tenha uma motivação para ter a vontade de aprender e praticar de forma racional, critica e com sapiência o que aprendeu na escola libertária e com a sua vivência para a sua vida. A escola não deve ser uma máquina de reproduzir um ser alienado, a escola não pode ser um aparelho de sustentação elitista e de perpetuação de sistema atrelado ao mais ajustado e com melhor situação que tenha possibilidade de sobressair mais que outro dentro de uma sociedade tão injusta que temos nos moldes atuais nos países que ainda engatinha para um desenvolvimento e ser emergente de forma segura e com uma possibilidade que todos tenha uma educação igualitária, na sua pratica, na 
sua concepção do objetivo da escola pública, da função de empregar verdadeiramente um aprender democrático e com todo esse aparato ser uma escola libertária de dogmas e estigmas que vem assolando a questão social mundial que é o analfabetismo funcional e regular. 


\section{4 - DESENVOLVIMENTO}

A forma como é tratada a educação nos tempos contemporâneo, com metodologias ainda com preceitos da época do ensino tradicional, onde a questão do aprender consiste em forma de conhecimento bancária, onde o saber consiste em limitação do que aprender para satisfazer o sistema que ostenta o poder, de uma educação vinculada as quatro paredes, sem uma contextualização do conhecimento prévio para o conhecimento sistemático tradicional, uma educação de ostentação de status de quem ensina, de quem coordena e de quem gerencia para seres majoritários e tratados como a menos importante no processo ensino aprendizagem que são os alunos.

Uma educação que a importância são empregos de metodologias e conteúdo para a questão profissional de quem está aprendendo sem preocupar com o pensamento racional, social, coletivo e crítico de quem está precisando ser um ser crítico, participativo e transformador de dogmas e de estigma no decorrer do seu desenvolvimento e crescimento com um ser vivo e social.

A educação sempre tem uma ideologia enganadora de acordo o que propõe governantes e dirigentes educacionais para o crescimento da educação moderna, progressiva e transformadora. É uma máscara enganadora no papel e na pratica, escola alienada a grande quantidade de conteúdos que muitas vezes são transmitido de forma incompleta e errônea, sem uma pluralidade de mecanismo em âmbito regional, estadual e nacional, imperando o que podemos chamar de uma educação elitista e singular. Vejamos o processo avaliativo do saber desse educando que consiste em uma nota quantitativa, uma avaliação que diz processual, democrática e igualitária e na sua realidade é voltada para uma diferenciação peculiar para diferentes regiões, sem uma base curricular satisfatório que atinge todos os alunados de diferentes idades e séries. Uma questão de agravante na formação dos educadores que tem oportunidades de estarem em sala de aula pelos órgãos governamentais limitadas e apadrinhadas para conseguirem vagas em campos de pesquisa na esfera estadual e federal, ficando a mercê de quem está dentro dessas instituições responsáveis para tais capacitações e aperfeiçoamentos. Tiramos como exemplos países que tem uma tradição em preocupar com a qualidade da sua nação no que trata de metodologias inovadora para a sala de aula. Onde a maior preocupação está voltada para o crescimento e para o 
desenvolvimento intelectual e pessoal para refletir na questão profissional. Isso nos deixa em uma desvantagem de cem anos em retrocesso quanto trata de países como os tigres asiáticos, os países da Europa, Canadá, Estados Unidos da América e Chile. Muitas vezes preocupam com investimentos mirabolantes com uma educação de qualidade e não alcançando e muitos vezes, sem muitos gastos financeiro, só com estratégias metodológicas concretas podem alcançar uma educação de qualidade.

Outro fato marcante para isso pode ser relacionado a fatores históricos sociais de cada países, tendo como exemplo, quando um país foi colônia de exploração em vez de ser de expansão. A epistemologia da educação retrata, muitas vezes, na forma como cada governo interessa para desenvolver políticas públicas para melhor obter resultado do seu interesse ou da maioria da classe elitista no preparo de mão de obra qualificada, para serem "peões" e muitas vezes "escadas" para sustentar o interesse da minoria que ostenta o poder aquisitivo financeiro e social de uma sociedade. Procuram reformas mirabolantes, metas, planos, etc e para poder sustentar o interesse de uma educação capitalista, imperando a desigualdade educacional, econômica e social dentro de uma realidade que no mundo onde está sempre buscando uma igualdade de todo lado social, uma educação nos moldes de ver com maior clareza a função da educação na sua maior essência e finalidade para o crescimento do seu humano. Uma escola libertária, tem o poder de transformar um universo social, intelectual e racional de um indivíduo, faz com que esse indivíduo seja conhecedor do que é necessário para a sustentação física, intelectual e ser transformador em um universo carente de quem pensa no plural. Uma escola libertária e interacionista é capaz de mudar uma estrutura convencional para uma estrutura multi direcional para o saber. Analisar uma linha de pensamento que diz Michel Foucault que "as instituições pedagógicas são para reproduzir sujeitos" para Foucault, é na escola que o sujeito nasce e que os moldes de um escola direcionada ideologicamente, pode fazer com que o sujeito seja um mero coadjuvante em um mundo social capitalista.

Foucault, nas suas publicações, faz com a educação seja vista no ponto arqueológico, genealógico e ético e ver claramente como isso se relaciona para ter uma escola libertária, sem uma tendência de classe social e sem uma concepção política ideológica, porém, a instituição escola, nos moldes da educação do poder, faz com que seja um mecanismo de alienação e de condução de tendências 
humanas no universo social. Quando trata do tema arqueológico, está mostrando a história da humanidade e o poder do mais forte, de quem tem a concepção da esperteza e da sapiência, é a relação do homem com o homem, quando trata da genialidade, vem à tona a questão da capacidade humana de transformar e de ser transformado, tanto para o lado positivo quanto para o lado negativo, vai depender da concepção de quem tem a força da persuasão e mostra claramente o poder e o lado ético vem da questão moral, do poder, do saber científicos, humanos e de se relacionar entre si com sapiência e moral. Segundo Faucault, esses três elementos proporciona o saber para que a consistência do conhecimento humano e é nesse ponto que entra a instituição escolar no processo da transformação desse homem.

\begin{abstract}
Para aplicar Foucault a problemas educacionais, é preciso ter em mente que se está fazendo "um deslocamento conceitual" de seu pensamento, ou seja, é preciso tomar o instrumental que Foucault aplica em outro campo e deslocá-lo para a área da educação. Sendo assim, considerando a temática da subjetividade como a principal preocupação do filósofo, podemos tomar suas considerações sobre o sujeito e aplicá-las à escola, uma vez que este conceito também é chave nas discussões sobre educação, procurando realizar uma crítica a essa instituição avaliando a sua função no meio social. Desse modo, pelo viés da subjetividade, do assujeitamento do sujeito pelas instâncias de poder, das suas relações com o saber e o poder, e também da questão ética, é possível trabalhar proveitosamente a filosofia foucaultiana aplicando-a à educação e à escola. (GALLO, 2011)
\end{abstract}

Na concepção de Foucault, a educação orientada por uma escola que não tem um poder libertário para transformar o sujeito para uma concepção crítica, inovadora, transformadora e com a capacidade de poder moidificar situações que faz com que ele, o sujeito não tenha capacidade de ser um ser, moral, ético, ideológico e de capacidade de transpor adversidades para ter uma vida adequada nos moldes natural de uma sociedade. A escola será uma mera sustentação da elite, da alienação do mais forte e do que vai ostentar o poder para diferenciar classe social e de condição humana.

Pierre Bourdieu tem uma ideologia quase similar à de Michel Foucoult, quando retrata a educação e a pratica pedagógica como um processo de libertar o sujeito para uma vida democrática e de uma condição igual para que possa enfrentar de justa igualdade no campo social com aqueles que tem uma vida privilegiada com dinheiro, tempo de poder estudar com mais eficiência e sem preocupar com a desigualdade social e neste termos ele afirma que: 
Supunha-se que por meio da escola pública e gratuita seria resolvido o problema do acesso à educação e, assim, garantida, em princípio, a igualdade de oportunidades entre todos os cidadãos. Os indivíduos competiriam dentro do sistema de ensino, em condições iguais, e aqueles que se destacassem por seus dons individuais seriam levados, por uma questão de justiça, a avançar em suas carreiras escolares e, posteriormente, a ocupar as posições superiores na hierarquia social. A escola seria, nessa perspectiva, uma instituição neutra, que difundiria um conhecimento racional e objetivo e que selecionaria seus alunos com base em critérios racionais. (BOURDIEU, 1998)

Pode afirmar que o autor via de formar renovadora o papel da instituição escolar pública como uma opção salvadora daqueles que buscavam a aprendizagem igualitária para poder disputar a sua sobrevivência dentro de uma classe social. Porém, a instituição escolar foi transformada para a sustentação de dogmas e estigmas que sobressaia no seu currículo e na pratica pedagógica a alienação do indivíduo para ser algo de sustentação para aquele que tinha o poder. Segundo Bourdieu:

\begin{abstract}
Simplesmente, seleciona os mais talentosos a partir de critérios objetivos. Bourdieu questiona frontalmente a neutralidade da escola e do conhecimento escolar, argumentando que o que essa instituição representa e cobra dos alunos são, basicamente, os gostos, as crenças, as posturas e os valores dos grupos dominantes, dissimuladamente apresentados como cultura. A escola teria, assim, um papel ativo - ao definir seu currículo, seus métodos de ensino e suas formas de avaliação - no processo social de reprodução das desigualdades sociais. Mais do que isso, ela cumpriria o papel fundamental de legitimação dessas desigualdades, ao dissimular as bases sociais destas, convertendo-as em diferenças acadêmicas e cognitivas, relacionadas aos méritos e dons individuais. (BOURDIEU, 1998)
\end{abstract}

A escola libertadora, fazendo uma análise do que diz Bourdieu, devia ser o principal mecanismo de libertação para que o indivíduo possa interagir e sobreviver as injustiças sociais que são tratadas simplesmente por uma máscara que diz que a instituição escolar é uma entidade democrática e libertadora. 


\section{5 - CONCLUSÃO}

Através das pesquisas feitas das obras dos autores mencionados neste ensaio e pelo conhecimento adquirido durante os estudos na academia, pode entender que a educação e a instituição escola ainda continua com uma metodologia que há muito tempo não foi inovada, que os professores não tem por parte do sistema uma formação continuada na sua totalidade, poucos conseguem obter vagas para a tal sonhada formação continuada pública, a educação e a instituição escolar continua tendo uma ideologia que favorece a elite, os burgus, os senhores do poder do sistema e fazendo com que o indivíduo fica a cada vez mais mercê na base inferior da pirâmide etária da classe social de uma sociedade. Neste contexto, é preciso que tenha uma política pública voltada com seriedade, com mais responsabilidade e fiscalização no processo com que possa elaborar uma educação e uma instituição escolar voltada para ter uma democracia, uma liberdade e igualdade no seu sistema na elaboração de curriculum, não atender ideologia religiosa, partidária e nem de cunho social financeiro, de uma base nacional com verdadeira intensão de promover uma educação e escola de qualidade para todos, não tendo uma distinção da instituição escolar pública da privada. Uma educação e instituição inovadora e libertadora. 


\section{6 - REFERÊNCIA BIBLIOGRÁFICA}

ALMEIDA, L.R. "Wallon e a educação “. In: ALMEIDA, L.(org.) e MAHONEY, A.A. (org.). Henri Wallon - Psicologia e Educação. São Paulo, SP: Edições Loyola, $2^{a}$ edição, 2002.

BORDIEU, Pierre. A reprodução. Rio de Janeiro: Francisco Alves, 1992.

. A economia das trocas simbólicas. São Paulo: Perspectiva, 1987.

. Escritos de Educação. Petrópolis: Vozes, 1998.

FOUCAULT, Michel. Microfísica do poder. Rio de Janeiro: Edições Graal, 1979.

. Vigiar e punir: nascimento da prisão. Petrópolis: Vozes, 2004.

GALLO, Sílvio; ASPIS, Renata Lima. Foucault e a educação. Coleção Filósofos e Educação. São Paulo: Paulus, 2011, DVD. 1 entrevista (60 min), widescreen, color.

Michel Foucault - Um crítico da instituição escolar. Revista Nova Escola, São Paulo, edição especial 10/2008.

O pensador de todas as solidões. Revista Educação - Especial Foucault pensa a educação, São Paulo, v. 3, p. 16-25.

PARO, Vítor Henrique. Educação como exercício do poder: crítica ao senso comum em educação. 2 ed. São Paulo: Cortez, 2010.

PINHEIRO, M. M. Emoção e afetividade no contexto da sala de aula: concepções de professores e direções para o ensino. Dissertação de Mestrado, Pontifícia Universidade Católica, São Paulo, 1995.

TRAGTENBERG, Maurício. A escola como organização complexa. In: GARCIA, Walter (org.). Educação Brasileira Contemporânea: organização e funcionamento. São Paulo: McGraw-Hill do Brasil, 1976, p. 15-30. 